\title{
1000 at 1000: The effect of electric field and pressure on the synthesis and consolidation of materials: a review of the spark plasma sintering method
}

\author{
Zuhair A. Munir ${ }^{1, *}$ \\ ${ }^{1}$ Department of Materials Science and Engineering, University of California, Davis, CA 95616, USA
}

Published online:

10 July 2020

(C) Springer Science+Business

Media, LLC, part of Springer

Nature 2020

\section{Introduction}

This Editorial is part of the celebration of a milestone for the Journal: the publication of its 1000th issue. The celebration also highlights published papers that received 1000 or more citations, hence "1000 at $1000 . "$ Our review article on the SPS process was such a paper [1].

While it is generally the case that review articles such as ours receive higher citations than regular papers, the nature of the field and its rate of development also play important roles. The high citations of our article are, I believe, reflections of the high interest and widespread research activity in this field worldwide.

On a personal note, my involvement in SPS research was an outcome of work I did back in the 1970s on electric field effects on various materials processes. I started by looking at the effect of an electric field on the sublimation of ionic single crystals, because such crystals have a surface charge. We looked not only at effects on sublimation rates, but also on changes in evaporation surface ledge dynamics and morphology. At the time the research seems rather esoteric, "what practical benefit does the evaporation of sodium chloride have?", a well-meaning colleague once asked. Fortunately, the funding agency, NSF, saw our research in a different light and provided a major encouragement by awarding me the Creativity in Research Award, twice. The work continued, examining field effects on growth and orientation of crystals and on the formation, mobility, and distribution of crystalline defects.

In the 1980s a new area of research, self-propagating high-temperature synthesis, SHS, became the focus of widespread investigations in the USA and elsewhere. It started earlier in the former Soviet Union as an outcome of research on rocket fuels.

Address correspondence to E-mail: zamunir@ucdavis.edu 
DARPA and the Department of Energy funded our work, which quickly involved the use of electric fields to activate such reactions. With the application of a field it was possible to achieve goals not possible with the ordinary SHS process. Subsequently the use of electric field in SHS became well known and widespread. Recollections from those days include an invitation to visit the Institute of Structural Macrokinetics in the then Soviet Union with a stay at the USSR Academy of Sciences Hotel in Moscow, not far from Red Square, and a trip to Alma Ata the capital of the Soviet Republic of Kazakhstan to give a presentation at a conference. Another unforgettable recollection for me from the heydays of the SHS research is an international conference held in China, at which I presented findings on field-activated SHS. The conference was held on a ship which cruised from the city of Wuhan up the Yangtze River through the Three Gorges to Chongqing. That was before the completion of the major dam on that river.

It was at an earlier SHS meeting that I met Professor Manshi Ohyanagi of the Ryukoku University in Japan, who much later became a co-author of our review article cited above. A collaboration (and friendship) initiated with him a long time ago continues to the present.

It was some time later that I learned about the new SPS process and read about its many accomplishments in Japan. The fact that the process utilizes an electric current was of special interest to me, having had involvement in similar work for more than a decade. I managed to write a successful proposal to the Army Research Office (ARO) that included the acquisition of an SPS unit. The Japanese company (Sumitomo) that installed the unit in my laboratory told me that our SPS was the first in the Western Hemisphere. That was back in the 1990s.

Once it became known that I have such a facility, a wave of interest from around the world emerged. As a consequence, our facility became a center for international collaboration with visiting scholars from France, Germany, Japan, China, Italy, Brazil, UK, Korea, Turkey, Mexico, Belgium, and Singapore. The second co-author of our cited paper, Dr. Anselmi-Tamburini, was one of the visiting scholars.

Initially my research with the collaborators focused on the fundamental aspects of the SPS process, aiming to provide an understanding for the various observations attributed to it. Over time a large number of findings came out of those investigations with similar number of publications. The Editor of the Journal of the American Ceramic Society invited me to write a Feature Article on the SPS process; the article was published in 2011 [2]. The international collaboration mentioned above not only brought scientific benefits but helped forge lasting friendships with wonderful people from all corners of the world. The organizers of the Fourth International Workshop on SPS, which was held in Cagliari (Sardinia, Italy), kindly dedicated that meeting and its Proceedings Book [3] to me for my work on the SPS process.

At present SPS facilities exist in large numbers all over the world; estimates range from 1300 to 1400 , with companies, making variations of the SPS equipment, located in Japan, the USA, Germany, China, and South Korea. The topic has been and continues to be a major feature at international meetings, such as the PacRim conferences, and the main focus of symposia and workshops, such as the International Conference on SPS to be held in Japan in 2022 (postponed from 2021 because of COVID-19).

Writing this Editorial led to examining the current status of the SPS process, which in turn led to the writing of the Invited Viewpoint: Perspectives on the Spark Plasma Sintering Process, which will follow shortly. In it, Manshi Ohyanagi and I discuss the phenomenal success of the spark plasma sintering (SPS) process, providing a historical account, presenting an overview of the accomplishments attributed to the process, and highlighting selected examples of these.

\section{References}

[1] Munir ZA, Anselmi-Tamburini U, Ohyanagi M (2006) The effect of electric field and pressure on the synthesis and consolidation of materials: A review of the spark plasma sintering method. J Mater Sci 41:763-777. https://doi.org/10. 1007/s10853-006-6555-2

[2] Munir ZA, Quach DV, Ohyanagi M (2011) Electric current activation of sintering: a review of the pulsed electric current sintering process. J Am Ceram Soc 94:1-19

[3] Cao G, Estournes C, Garay J, Orru R (eds) (2019) Spark Plasma Sintering: Current Status New development and challenges. Elsevier, Amsterdam

Publisher's Note Springer Nature remains neutral with regard to jurisdictional claims in published maps and institutional affiliations. 